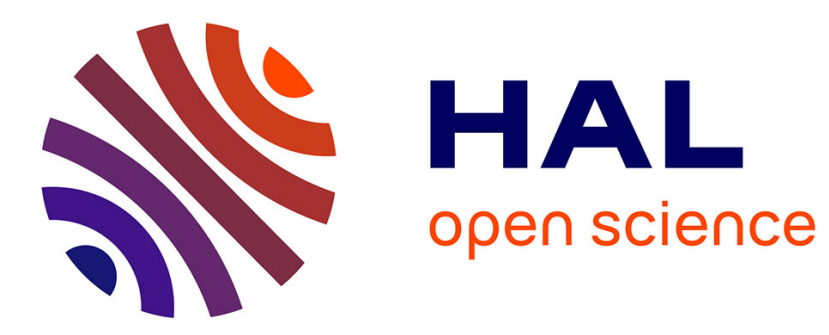

\title{
Selection of a green manufacturing process based on CAD features
}

\author{
Raoudha Gaha, Bernard Yannou, Abdelmajid Benamara
}

\section{To cite this version:}

Raoudha Gaha, Bernard Yannou, Abdelmajid Benamara. Selection of a green manufacturing process based on CAD features. International Journal of Advanced Manufacturing Technology, 2016, 87 (5), pp.1335-1343. 10.1007/s00170-015-7499-y . hal-01271926

\section{HAL Id: hal-01271926 \\ https://hal.science/hal-01271926}

Submitted on 20 Sep 2016

HAL is a multi-disciplinary open access archive for the deposit and dissemination of scientific research documents, whether they are published or not. The documents may come from teaching and research institutions in France or abroad, or from public or private research centers.
L'archive ouverte pluridisciplinaire HAL, est destinée au dépôt et à la diffusion de documents scientifiques de niveau recherche, publiés ou non, émanant des établissements d'enseignement et de recherche français ou étrangers, des laboratoires publics ou privés. 


\title{
Selection of green manufacturing process based on CAD-features
}

\author{
Raoudha GAHA, Bernard YANNOU and Abdelmajid BENAMARA
}

\begin{abstract}
Environmentally Conscious Manufacturing Process (ECMP) has become an obligation to the environment and to the society itself, enforced primarily by governmental regulations and customer perspective on environmental issues. ECMP involves integrating environmental thinking into new product development. This is especially true in the Computer Aided Design (CAD) phase which is the last phase in the design process. At this stage more than $80 \%$ of choices are done. Feature technology (FT), the core of CAD phase, is then used to integrate environmental aspects. Also, integrations realized on CAD systems, such as Computer Aided Manufacturing (CAM), Computer Aided Process Plan (CAPP) and Product Life Management (PLM) are explored to eco-design products. This paper presents a new methodology for the selection of a green manufacturing process based on $\mathrm{CAD}$ features and CAD/CAM/CAPP/PLM integrations. First we present an overview of works using FT in CAD phase to reduce the environmental impacts of a manufacturing process. Secondly, we propose an approach based on FT for selecting an ECMP to promote new simple eco-design tool which helps inexperienced eco-designers. Finally, a case study is considered to validate the proposed approach and results are commented.
\end{abstract}

Keywords: Green manufacturing process / CAD model / LCA / Feature technology / Scenarios.

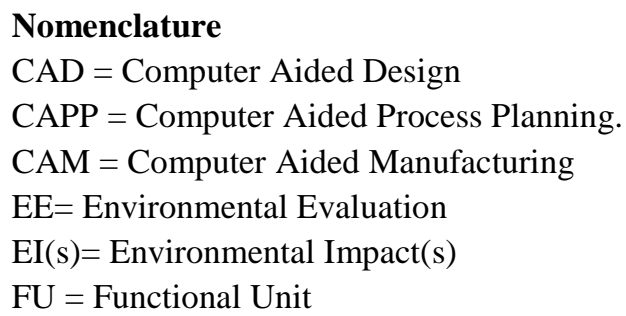

BENAMARA'.

\author{
ECMP = Environmentally Conscious \\ Manufacturing Process \\ EIs $=$ Environmental Impacts \\ FT $=$ Feature Technology \\ FUC $=$ Functional Unit Coefficient \\ IPO = Input-Process-Output \\ LCA = life Cycle Assessment \\ LCI = Life Cycle Inventory \\ SLCA $=$ Simplified Life Cycle Assessment
}

\section{Introduction}

Face to the growing awareness of environmental concerns issued from human activities, eco-design aims at offering a comprehensive approach for the products and services development field, especially during the design process [1-2]. However in the late detailed design phase, the designer action field is seriously limited as he/she may handle few degrees of freedom. Manufacturing process is one of these degrees of freedom for CAD designer. In the literature environmentally conscious manufacturing process is widely studied; Ilgin and Gupta classified more than 500 researches on that domain [3]. However, fewer methods have been developed for an environmental evaluation in CAD phase of possible manufacturing process plan scenarios to facilitate decision making. In this phase, features are the core of a geometric model. According to Bidarra et al. [4], modeling features compared to conventional geometric modeling enables the combination of functional and engineering information on the form in a product model. For Ghodous [5], this Feature technology (FT) facilitates the integration between different phases of product development such as design and manufacturing. FT serves also to integrate CAD systems and Ecodesign tools such as Life Cycle Assessment (LCA) software. Hence we propose a new methodology based on features to generate possible process plans from one side and to evaluate environmentally each scenario in order to select the greenest one on the other side.

In this paper we start by a state of the art of benefits attempted by the integration between CAD and Computer aided process plans (CAPP) based on FT. Secondly, we present a literature review of works integrating environmental evaluation into manufacturing process. Thirdly, we propose our approach. Finally we apply our methodology into a case study for validation. 


\section{Feature technology and environmentally conscious manufacturing process: Overview}

A feature is a local shape of a product directly related to the manufacturing process. Smith and Dagli [6] define features as high-level design primitives with their attributes, their qualifiers and restrictions which affect the functionality and/or the ability for the product to be manufactured. It was used to reduce the environmental impact playing with different parameters in the production phase. Works, evaluating Environmental Impacts (EIs) of production processes, found in the literature can be divided into three group; (1) selection of green process planning from different alternatives (2) selection of green process parameters such as cutting fluid or machining tool. The integration of Computer Aided Design (CAD) and Computer Aided Process Planning (CAPP), as realized by Yifei et al. [7], represents a success in generating different possible process plans in real time and their corresponding EIs. It becomes possible to select the most appropriate machining tools with low EIs and also the optimum machining scenario. These benefits are possible thanks to features models that provide the necessary data for a Life Cycle Inventory (LCI).

We present below the most important works that guided us.

\subsection{Analysis of CAD/CAPP integration with features}

The integration between CAD and CAPP (Computer Aided Process Plan) systems is based on Feature Technology (FT). Many researches are focused on this integration.

Based on feature technology, Jiang et al. propose an automatic process planning system for the quick generation of manufacturing process plans directly from CAD drawings [8]. Features are also used to identify the finish-cut machinable volume by getting the rough-machined part from the final part [9]. Moreover we find in literature different researches which are oriented to elaborate a process sequence in a CAPP for a component based on features. For examples, Yusof and Case [10] established a STEP compliant CAD/CAPP/CAM (Computer Aided Manufacturing) system for turning operations. Features are explored to select an optimal Setup plan machining features of prismatic parts [11]. Kumar presents a methodology that can model any given component using cut features (mimicking machining operation) and produce an optimal choice of machine tools for machining that component [12]. Deja and Siemiatkowsk [13] present a conceptual scheme which generates alternative process plans as a network.

\subsection{EIs evaluation of process plans and selection of the greenest one}

The evaluation of manufacturing environmental impacts is studied in most research works. It is aimed at limiting or avoiding the use of processes which have an impact on ecosystems, human health, etc. Various proposed approaches have been utilized to evaluate the environmentally oriented metrics of manufacturing processes, ranging from experimental investigations to the development of mechanical models. Jiang et al [14] present in their work an overview of these approaches. Then, they propose an environmental performance assessment method for manufacturing process plans. The method developed uses actual values for various environmental measures for the different operations in the plan to form an impact matrix.

Le Borhis et al. [15] developed a methodology based on a predictive model of flow consumption that is defined from the manufacturing path and the part CAD model.

Sheng et al. and Munoz et al. [16-18] analyze, in their respective work, the environmental impact of dissimilar waste streams. They apply a scoring system which evaluates factors such as toxicity, carcenogenesis, irritation, flammability, and reactivity, reducing complexity of processing alternatives through a feature-based approach. A hierarchical part planning strategy for environmentally conscious machining is developed [19], and it is shown that a feature can be machined with different scenarios. The purpose is to choose the least impactful set of machining sequences. Figure 1 shows the example considered by Sheng [16] to demonstrate the influence of changing the order of machining sequences on environmental impacts of a production process. In [16], Sheng decomposes the environmental impact component into "micro" analyses of individual features [19] and "macro" analyses of feature interactions [20]. To evaluate the resources and environment attributes of manufacturing process, Zhang, H.et al. [21] present an IPO (Input-Process-Output) model and an evaluation index system in order to select the greenest process plan.

More than the evaluation of EIs, features are useful for selecting green process planning, such as the multi-objective optimization decision-making framework model of process planning for green manufacturing established by $\mathrm{Cao}$ et al. [22] to put forward a new process planning strategy for green manufacturing and to develop a process planning software tool. In 2006, Tan et al [23] developed a new production process which determines a method focusing on sustainable manufacturing. It is based on case-based reasoning, expert systems, and feature technology for designing a new component's 
process flow. A sustainable development assessment is the basis of this process flow.

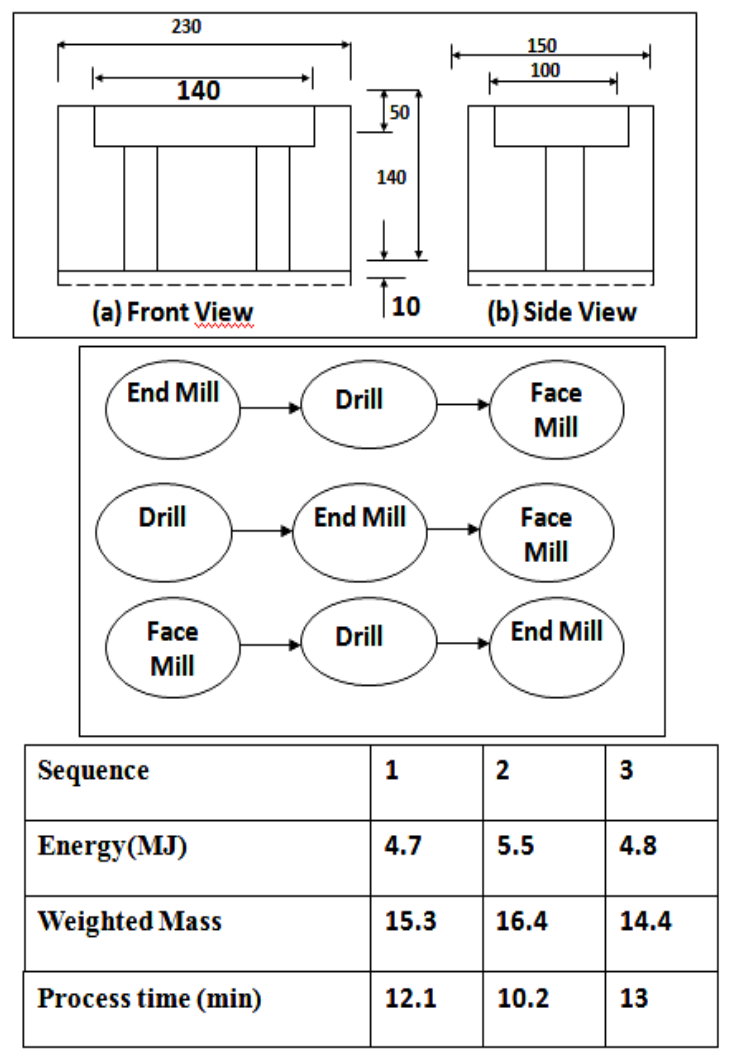

Fig.1 Influence of machining sequences order on the EIs of a part consisting of three types of features: a pocket, a hole and a finished planar face [16]

Zhao et al. [24] also propose a method for environmentally conscious process planning. The method begins with an existing process plan, and then identifies impactful process steps, and associated design features, in terms of manufacturing cost and environmental impact. Alternative processes that can achieve these features are then considered to generate alternative process plans. This might be useful to integrate into CADLCA integrated systems to help a designer comparing different alternatives till features attribution. Nawata et al. [25] propose a new lifecycle design system specifically applicable to machined parts. The system automatically generates life-cycle assessment (LCA) feedback for the design process through the effective linkage of life-cycle inventory data with computer-aided design/computer-aided manufacturing (CAD/CAM) data by feature-based modeling. Hence, a determining idea coming out of CAD/CAM/CAPP integration is the possible generation of different machining scenarios.
Each scenario has environmental impacts related to the parameters of the process plan attributed. Feature technology, in CAD phase, can help the designer select, from possible alternatives, the greenest process.

\subsection{Selection of green process parameters}

Manufacturing process planning is based on a set of parameters such as cutting tool, cutting fluid, or machining tool. Tan, et al [26] used feature technology in selecting the most ecological cutting fluid, and machining tool because they are important parameters in developing green products. In a similar vein, the selection of an ecological machine tool is the aim of Jiang and Zhang's study [27], where they develop the model called Vector Projection Method. This method, based on feature technology, creates a reference index system to justify machine tool selection, by considering resource consumption and environmental impact due to part features which needs an energy input/expenditure (electric mechanic, pneumatic, etc.) to be realized. Estimating the required energy and optimizing it presents a challenge for green manufacture. Possible production energy consumption scenarios in a feature level are studied by Deshpande [28], and assessed through MT Connect standard methodology. Other process parameters, such as finish cut and feed rate generate EIs due to their relation to the part quality. Helu et al. [29], using feature technology, develop a methodology showing that the impact of green machining strategies such as part quality on achieved surface quality is most influenced by the finish cut(s) and feed rate. Improving part quality can also reduce life cycle EIs.

Zhang et al. [30], present a study on optimized principles of process parameters (such as cutting depth, cutting velocity and feed rate) for environmentally friendly machining austenitic stainless steel with high efficiency and little energy consumption.

CAD and CAPP integrations may also allow to define more Life Cycle scenarios during the detailed product-process definition of a part or assembling. It is, therefore, necessary to integrate these benefits into CAD-LCA integrated tools to perform environmental assessment in real time and also choose the greenest process plan from existing possible scenarios. These contributions can be accompanied by a green end of life with promotion of design phase disassembly and recyclability.

Figure 2 summarizes benefits achieved from CAD/CAM/CAPP integration by using FT. These benefits confirm the ability to enrich features with required LCA data. In this paper, we are interested in the manufacturing phase of a part life cycle. 


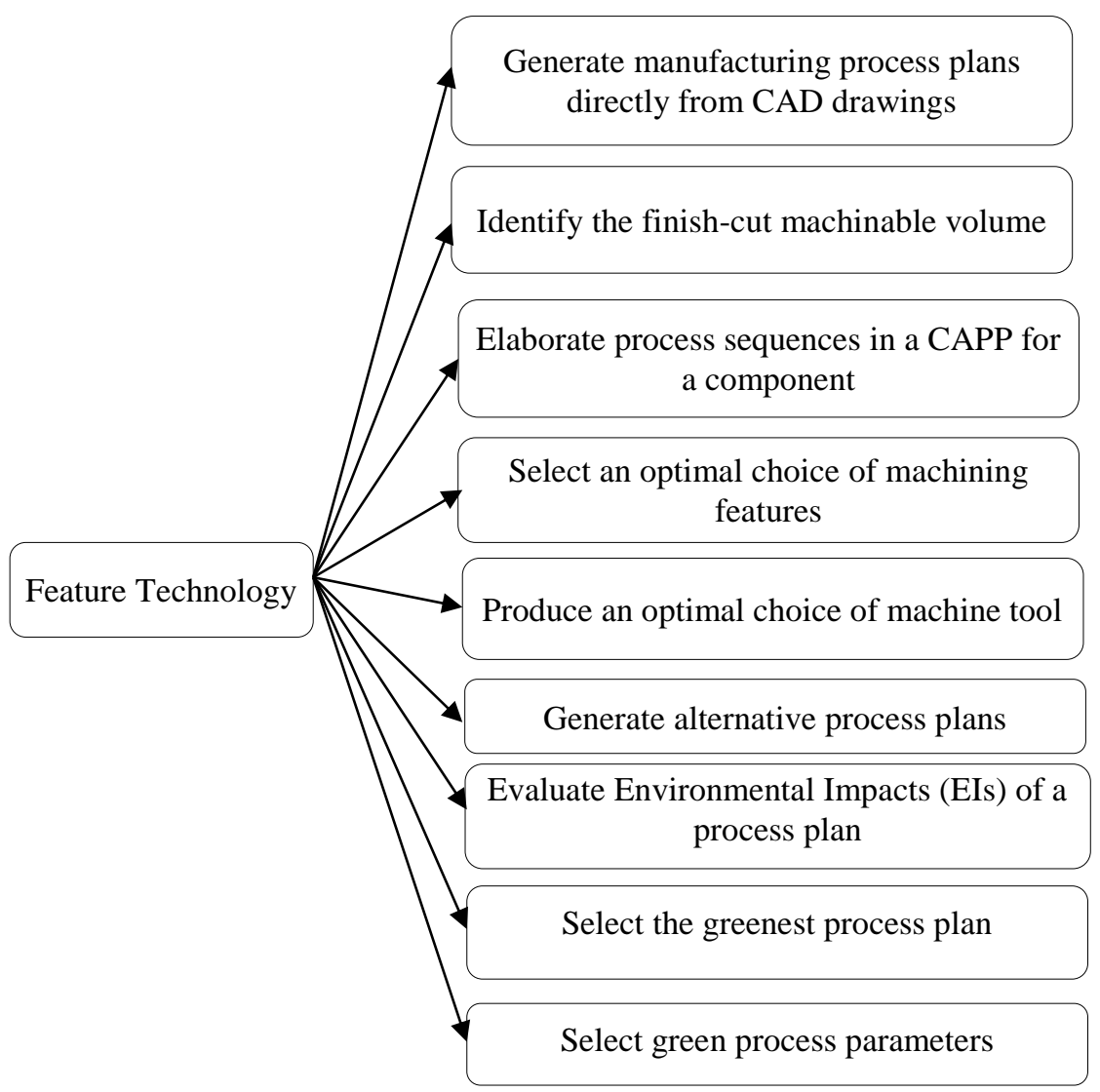

Fig .2 Benefits of CAD/CAM/CAPP integration based on FT

\section{Proposed approach}

In our methodology we explore feature technology to evaluate the environmental impact of a product manufacturing process from the geometric modeling phase by an LCA tool. In fact, it consists in giving the designer the machining environmental impact of the current CAD model once a feature is attributed. The methodology presented is an algorithm that allows the designer to see the machining environmental impact of each feature chosen in a real time and presents him an optimal scenario in terms of environment by using CAD, CAM, CAPP and PLM systems. These systems can provide many types of product information such as geometric and non geometric (material, tolerances or engineering constraints). CAM and CAPP systems can provide information about manufacturing processes and PLM systems can include the requirements phase, analysis and design stages, manufacturing, product launch, distribution, quality assurance, in-service maintenance and spare parts provisions. Some missing data are included in databases such as those of EcoInvent [31] and "Bilan Produit" [32] where impacts such as earlier manufacturing operations and raw materials processing are already included.

Hence, the extracted and included data are enriching features, in CAD phase, with different types of information in order to practice and LCA, which consists in four stages defined by standard organizations (ISO14040) [33]; goal and scope, life cycle inventories, life cycle analysis and result interpretation as shown in Figure 3.

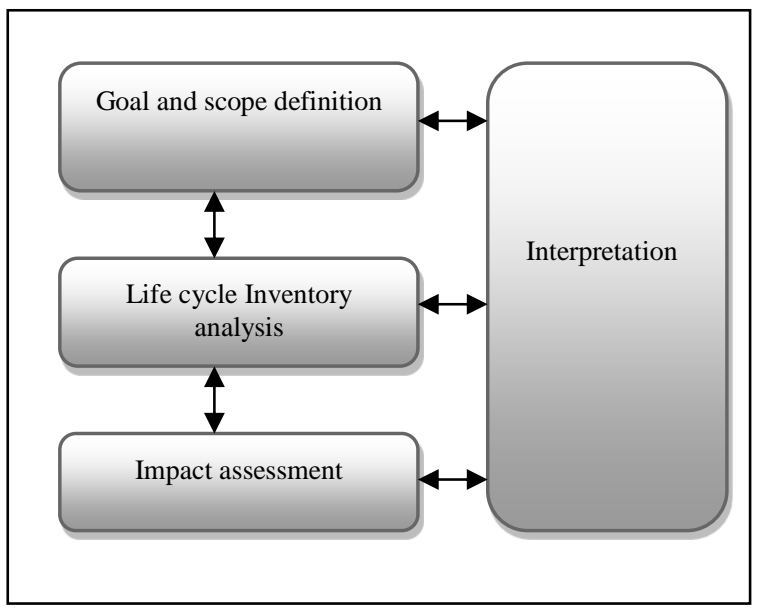

Fig. 3 LCA stages (ISO 14040)

Enriching feature make it a Life Cycle Inventory (LCI) model. This model can be used for an Environmental Evaluation during CAD phase.

Our approach is composed of seven steps as shown in figure 4 :

- The first step is done by the designer in selecti ng a feature from CAD system data base.

- In the second step, the designer designates a $\mathrm{m}$ 
aterial. The right material might be inexistent in CA D database, but could exist in LCA database. In this case, the designer can access to both databases.

- The third step is based on CAD/CAM/CAPP s ystems. In this step there is a generation of different possible alternative machining scenarios.

- In the fourth step, Environmental Evaluation ( $\mathrm{EE}$ ) is realized and the designer gives only the Func tional Unit (FU), which is established from the main technical characteristics of the product studied (we $p$ ropose the FU related to the whole product) and the necessary data for realizing Simplified Life Cycle A ssessment (SLCA) is extracted automatically from C $\mathrm{AD} / \mathrm{CAM} / \mathrm{CAPP}$ systems. Data extraction is done th roughout generic algorithm that will be described in future works. The environmental impact calculus is done based on Morbidoni's Work [34] where the $\mathrm{m}$ anufacturing part environmental impact can be calc ulated by the proposed simplified approach given by Equation 1:

$$
\begin{gathered}
\mathrm{LCA}_{\text {Part. manuf }}=\mathrm{LCA}_{\text {Energy consumption }}+\mathrm{LCA}_{\text {Waste material }} \\
\mathrm{LCA}_{\text {cutting fluid }}+\ldots+\sum \mathrm{n}_{\mathrm{i}=1} \mathrm{LCA}_{\text {feature. }} \text { (eq.1) }
\end{gathered}
$$

Where;

LCA Prod. manuf =environmental impact of part manufacturing phase

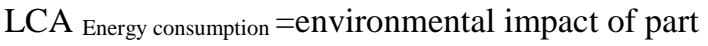
energy consumption during manufacturing process $\mathrm{LCA}_{\text {waste material }}=$ environmental impact of part waste material

LCA $_{\text {cutting fluid }}$ environmental impact of lubricant used for machining the part

LCA feature.i=total environmental impact of feature i.

The method used for calculus is the CML method [35]. It is a method which respects the standardized procedure of environmental assessment. In this met hod, environmental impacts are calculated along wit $\mathrm{h}$ four steps: classification, characterisation, normati on and assessment.

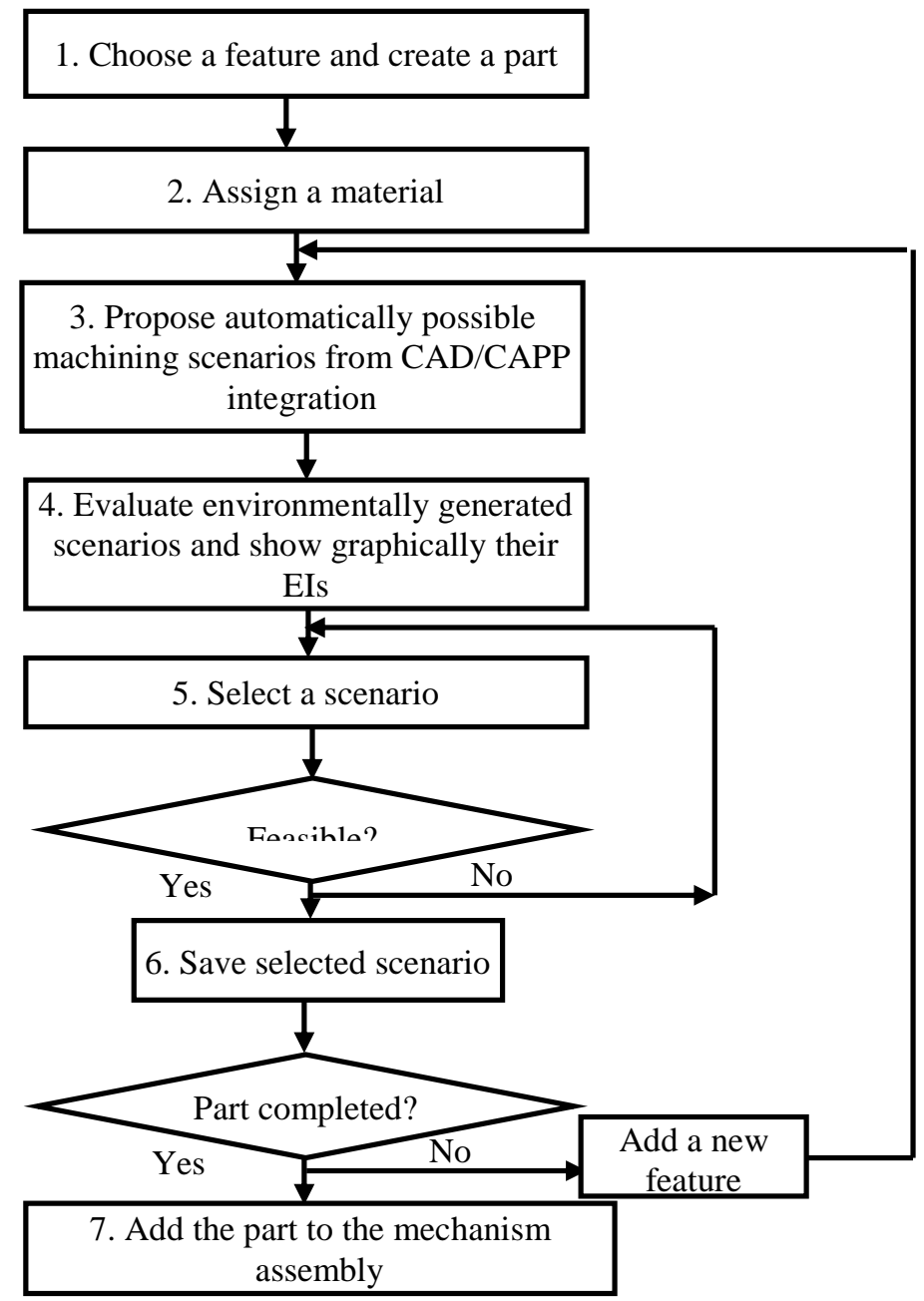

Fig.4 Proposed methodology for selecting green manufacturing process based on feature technology

After an environmental impact calculus of manufa cturing processes, a comparative graphic between sc enarios is shown to the designer. The graphic repres entation is with End-points Impacts (Resources, $\mathrm{Hu}$ man Health and Eco-system damages) in a Single $\mathrm{S}$ core. This allows the non environmental expert desi gner to understand Environmental Impacts (EIs). Th is step is the final stage of an LCA according to ISO 14040 [33].

- In the fifth step, a scenario is selected (the opti 
mum one). Therefore, a feasibility test is practiced; $\mathrm{i}$ $\mathrm{f}$ the selected scenario is feasible then step six is rea ched, else another scenario is selected and tested.

- The sixth step consists in saving the selected $\mathrm{m}$ achining scenario if the feasibility test is positive.

- The seventh step is reached if the test of finish ing designing part is positive; otherwise the last fou r steps will be redone (Steps 3, 4, 5 and 6).

The calculus, in this paper, is realized on global machining processes, in order to approve the feasibility of our approach. However, we propose, in our work $[36,37]$ a methodology based on process plan activities aiming at selecting the optimum scenario having the best compromise environmental impact versus cost.

Figure 5 represents a framework of a new Ecodesign tool, oriented green manufacturing, applying the approach proposed previously, which we name "Green-CAD". It is composed of a connector which collects necessary data for LCA tool from CAD, CAM, CAPP and PLM systems which collaborate together on the same part. Once the environmental evaluation is done, graphical representation is shown to the designer. The graphic allows to see, at the user interface, the optimal scenario from proposed ones.

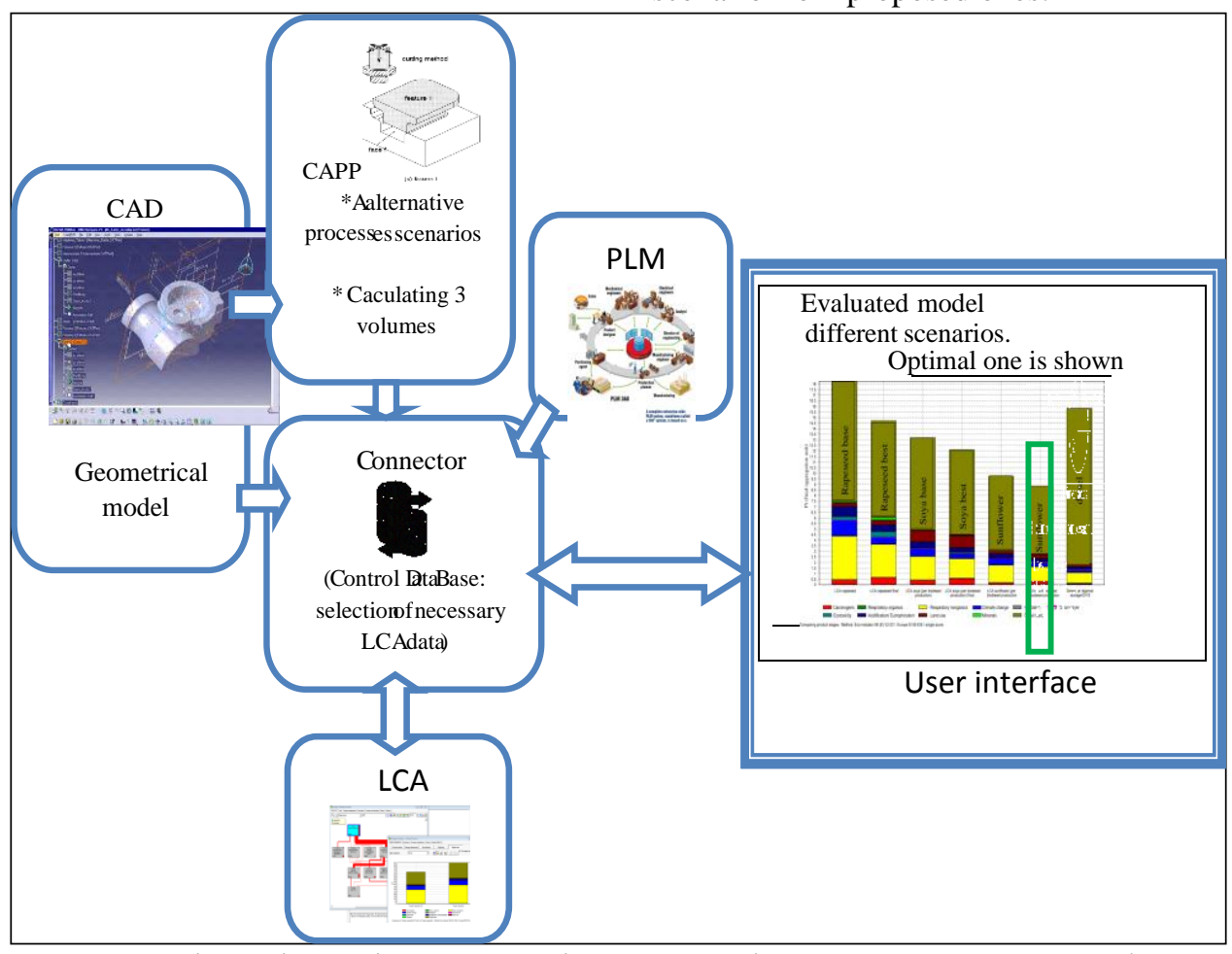

Fig.5 CAD/CAM/CAPP/PLM Integration Framework: “Green-CAD” Framework

\section{Case study}

To reach the final part, the designer assigns features. For each assigned feature, manufacturing scenarios can be generated, each scenario being associated with its own EIs. Our methodology, as shown before, consists of; firstly proposing alternative manufacturing scenarios after each feature selected, secondly evaluating environmentally proposed scenarios and finally comparing between the obtained results in order to help the designer choosing the most ecological one. We further illustrate the proposed methodology with a case study. We consider the part shown in the right side of figure 4 which is a part made of brass and weighting $1 \mathrm{~kg}$. Based on features, there are two models that can be used for the sample part; the design model and the process model. In our study we consider the process model, where each feature or a set of features requires a manufacturing process. By combinatorial rules and data extracted from integrated systems (CAM, CAPP and PLM) to CAD system, possible manufacturing scenarios are proposed. Then, based on the integrated CAD/LCA system, that we proposed previously, EIs of each scenario are assessed.

Based on features, the identification of geometric forms of the considered part allows to generate four possible scenarios to realize it, as shown in figure 6.

- Scenario 1: the part can be made by Molding, then Surfacing, then Inferior Milling and Superior Milling processes.

- Scenario 2: the part can be obtained only by Molding process.

- Scenario 3: the part can be made by "Molding", then Surfacing and Welding processes.

- Scenario 4: the part can be made by Molding, then Surfacing, then Drilling and Thread processes. 

Internationa/ Jaurna/ af Advanced Manufacturing Technology, dai: 10.1007/s00170-015-7499-y

A Simplified LCA is performed, by using the tool "Bilan Produit", which is a software developed by ADEME institution [30]. The database used was established in collaboration with EcoInvent Centre and the Swiss Centre for life Cycle inventories [29], in order to assess the environmental impact of each scenario and compare them. By using the CML method [35], calculated impacts are presented in the following categories considered for each step: Energy consumption NR (MJ eq), Use resources (kgSbeq), Greenhouse GWP 100 mod (kg CO2eq), Acidification (kg SO2 eq), Eutrophication (air ground water) (kg PO4eq), Photochemical pollution (kg C2H4), Aquatic Ecotoxicity (kg1.4-DBeq) and Human toxicity (kg 1.4-DB eq). These impact indicators are expressed in units incomprehensible by non environmental expert designers. The normation occurs by taking the ratio between the value of product's impact and the reference value of the normation. The normation chosen in this software takes as reference the daily consumption of an average European.

The results are expressed in points, in order to allow the designer to globally apprehend which is the most ecological scenario. For the final part, four machining scenarios are proposed, the comparison between their environmental impacts are shown in figure 7 which highlights that scenario 4 is the most ecological one.

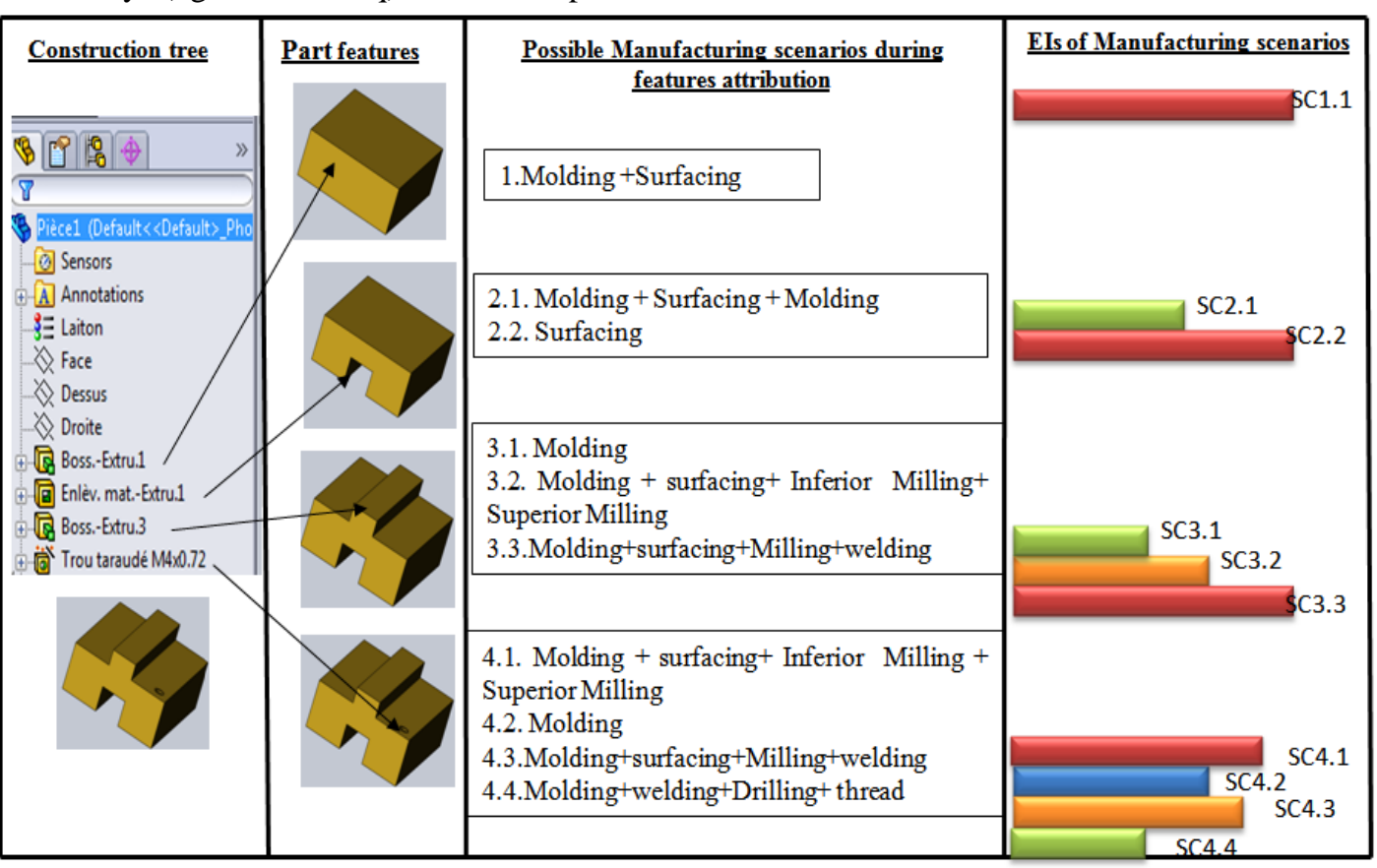

Fig.6 A model for generation and comparison of possible manufacturing scenarios for a part case study

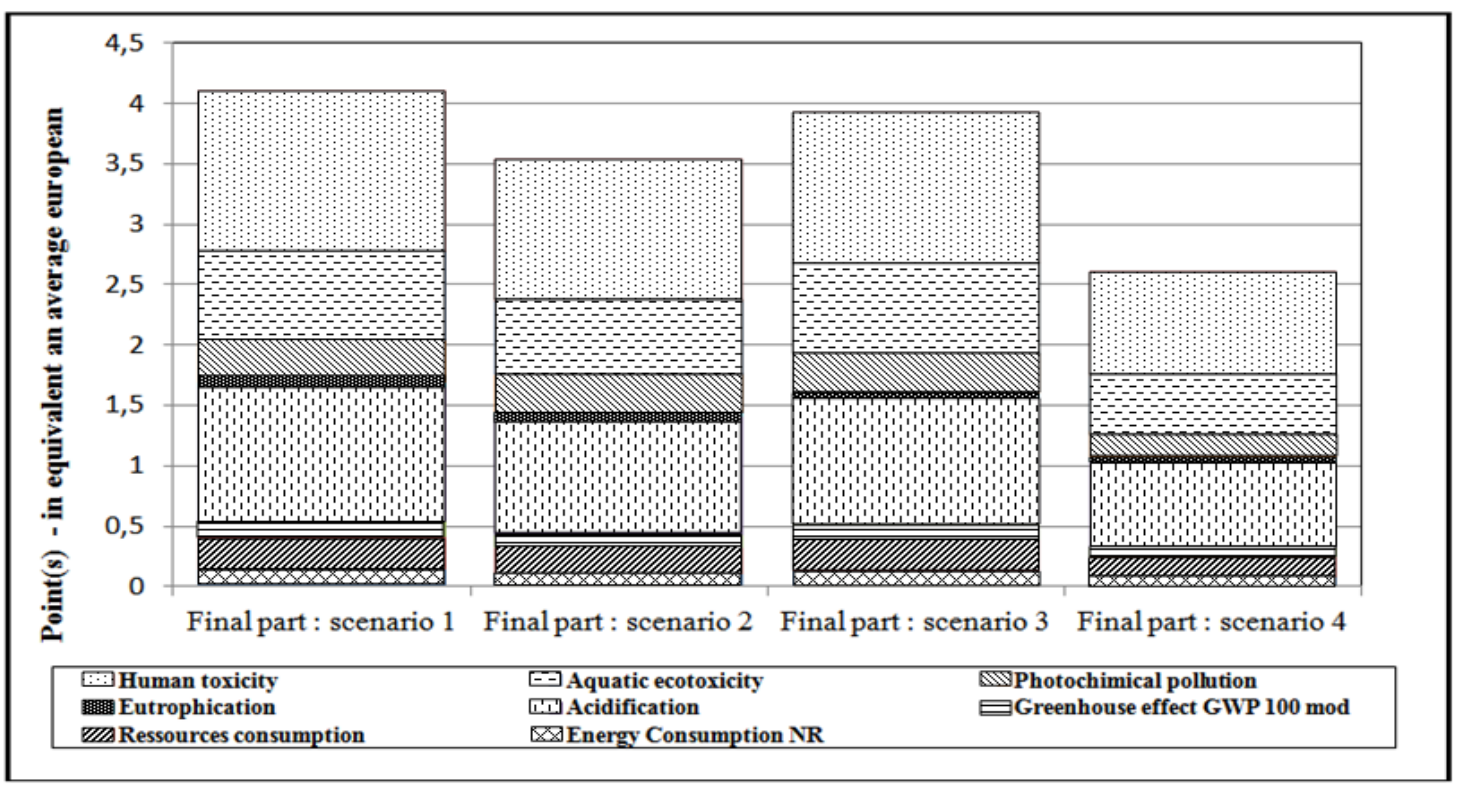

Fig.7 Comparison of environmental impacts of possible manufacturing scenarios for the final part 


\section{Conclusion}

This paper presents the necessity of lowering EIs of manufacturing processes. It recalls some researches aiming at helping designers choosing the ECMP in CAD phase. Feature technology is used, in generating scenarios in CAPP and for the choice of greenest ones in terms of environmental impacts. Our proposed approach, also, explores feature technology to evaluate environmentally possible manufacturing processes of a product from the geometric modeling phase by an LCA tool in real time. A case study is developed to show the manufacturing scenarios generation and their related environmental impacts, which are calculated with the CML method. From this work, we deduce that FT enables the efficient retrieval of necessary Life Cycle Inventory (LCI) data. Hence, as a continuation to be published, we are developing the concept of "eco-feature" to model design data integration in the detail design phase and prepare a mechanical product to real-time simplified LCAs.

\section{REFERENCES}

1. BREZET, J.C., (1997), Dynamics in Ecodesign prac tice, UNEP Industry and Environment. Vol. 20, $\mathrm{N}^{\circ}$ 1-2, pp. 21-24, Paris.

2. M.Janin (2000) Démarche d'éco-conception en entr eprise, un enjeu: construire la cohérence entre outils et processus, PHD THESIS ENSAM, 2000.

3. Ilgin, M. A., \& Gupta, S. M. (2010). Environmental ly conscious manufacturing and product recovery (E CMPRO): a review of the state of the art. Journal of Environmental Management, 91(3), 563-591.

4. Bidarra R. and Bronsvoort WF. (2000) Semantic fea ture modeling-Computer Aided Design. - 2000. -Vo 1. 32. - pp. 201--25.

5. Ghodous P. (1996) Modélisation Intégrée de Donné es de Produit et de Processus de Conception [Repor t] : Tech-report. - Lyon - FRANCE : Université Cla ude Bernard - Lyon1, 1996.

6. Smith A. E. and Dagli C. H. (1995) Manufacturing $f$ eature identification for intelligent design - Intellige nt Systems in Design and Manufacturing. - Boston, MA, USA, 1995. - 17-21. - pp. 213--230.

7. Yifei, T., Dongbo, L., Changbo, L., \& Minjian, Y. ( 2008). A feature-extraction-based process-planning system. The International Journal of Advanced Man ufacturing Technology, 38(11-12), 1192-1200.

8. Jiang, B., Lau, H., Chan, F. T., and Jiang, H. (1999) . An automatic process planning system for the quic $\mathrm{k}$ generation of manufacturing process plans directl $\mathrm{y}$ from CAD drawings. Journal of Materials Process ing Technology, 87(1), 97-106.

9. Arivazhagan A, Mehta NK, Jain PK, “A STEP AP 2 03/214 based Machinable Volume Identifier for Ide ntifying the Finish Cut Machinable Volumes from R ough Machined parts" Published in "International J ournal of Advanced Manufacturing Technology" Sp ringer Publishers Ltd. UK.Volume 42, Numbers 9-1 0 / June, 2009, P.No.850-872, DOI 10.1007/s00170
-008-1659-2. (L13-16)

10. Yusof, Y., and Case, K. (2008). STEP compliant C $\mathrm{AD} / \mathrm{CAPP} / \mathrm{CAM}$ system for turning operations. In $\mathrm{P}$ roceedings of the World Congress on Engineering a nd Computer Science (pp. 22-24).

11. Hebbal, S. S., and Mehta, N. K. (2008). Setup plann ing for machining the features of prismatic parts. Int ernational Journal of Production Research, 46(12), 3 241-3257

12. Kumar, E. (2010). Optimal choice of a machine tool for a machining job in cae environment (Doctoral di ssertation, Brunel University).

13. Deja, M., \& Siemiatkowski, M. S. (2012). Feature-b ased generation of machining process plans for opti mised parts manufacture. Journal of Intelligent Man ufacturing, 1-16.

14. Jiang, Z., Zhang, H., \& Sutherland, J. W. (2012). D evelopment of an environmental performance asses sment method for manufacturing process plans. The International Journal of Advanced Manufacturing T echnology, 58(5-8), 783-790.

15. Le Bourhis, F., Kerbrat, O., Hascoët, J. Y., \& Mogn ol, P. (2013). Sustainable manufacturing: evaluation and modeling of environmental impacts in additive manufacturing. The International Journal of Advanc ed Manufacturing Technology, 69(9-12), 1927-193 9.

16. Sheng, P., Srinivasan, M., and Kobayashi, S. (1995) . Multi-objective process planning in environmental ly conscious manufacturing: a feature-based approa ch. CIRP Annals-Manufacturing Technology, 44(1) , 433-437.

17. Munoz, A. A., and P. Sheng (1995). "An analytical approach for determining the environmental impact of machining processes." Journal of Materials Proce ssing Technology 53.3 (1995): 736-758.

18. Sheng, P., Srinivasan, M., and Chryssolouris, G. (19 96). Hierarchical part planning strategy for environ mentally conscious machining. CIRP Annals-Manu facturing Technology, 45(1), 455-460.

19. Srinivasan, M., and Sheng, P. (1999). Feature-based process planning for environmentally conscious ma chining-Part 1: microplanning. Robotics and Comp uter-Integrated Manufacturing, 15(3), 257-270.

20. Srinivasan, M., and Sheng, P. (1999). Feature based process planning in environmentally conscious mac hining-Part 2: macroplanning. Robotics and Compu ter-Integrated Manufacturing, 15(3), 271-281.

21. Zhang, H., Zhang, X. G., and Wang, Y. H. (2010). T he Evaluation of Resources and Environment Attrib utes of Manufacturing Process Based on Scatter De gree Combination Evaluation Method. Applied Mec hanics and Materials, 37, 1466-1472.

22. Cao, H. J., Liu, F., He, Y., and Zhang, H. (2002). St udy on model set based process planning strategy fo $r$ green manufacturing. Jisuanji Jicheng Zhizao Xito ng/Computer Integrated Manufacturing System(Chi na), 8(12), 978-982.

23. Tan, X., Liu, F., Dacheng, L., Li, Z., Wang, H., and Zhang, Y. (2006). Improved methods for process ro uting in enterprise production processes in terms of 
Gaha R., Yannou B., Benamara A. (2015) 'Selection of green manufacturing process based on CAD-features', The Internationa/ Jaurna/ af Advanced Manufacturing Technology, dai: 10.1007/s00170-015-7499-y

sustainable development II. Tsinghua Science and T echnology, 11(6), 693-700

24. Zhao, F., Murray, V. R., Ramani, K., and Sutherlan d, J. W. (2012). Toward the development of process plans with reduced environmental impacts. Frontier $\mathrm{s}$ of Mechanical Engineering, 1-16.

25. Nawata, Shoji, and Tojiro Aoyama (2001). "Life-cy cle design system for machined parts-linkage of LC I data to CAD/CAM data." Environmentally Consci ous Design and Inverse Manufacturing, 2001. Proce edings EcoDesign 2001: Second

26. Tan, X. C., Liu, F., Cao, H. J., and Zhang, H. (2002 ). A decision-making framework model of cutting fl uid selection for green manufacturing and a case stu dy. Journal of materials processing technology, 129 (1), 467-470.

27. Jiang, Z., and Zhang, H. (2006, November). A vecto $r$ projection method to evaluating machine tool alter natives for green manufacturing. In Technology and Innovation Conference, 2006. ITIC 2006. Internatio nal (pp. 640-643). IET.

28. Deshpande, A., Snyder, J., and Scherrer, D. (2011, J une). Feature level energy assessments for discrete $p$ art manufacturing. In 39th Annual SME North Ame rican Manufacturing Research Conference (NAMR C).

29. Helu, M., Behmann, B., Meier, H., Dornfeld, D., La nza, G., and Schulze, V. (2012). Impact of green ma chining strategies on achieved surface quality. CIRP Annals-Manufacturing Technology.

30. Zhang, Y., Zou, P., Li, B., \& Liang, S. (2015). Stud $\mathrm{y}$ on optimized principles of process parameters for environmentally friendly machining austenitic stain less steel with high efficiency and little energy cons umption. The International Journal of Advanced Ma nufacturing Technology, 1-11.

31. Frischknecht, R., Jungbluth, N., Althaus, H. J., Dok a, G., Heck, T., Hellweg, S., ... \& Wernet, G. (2007) . Overview and methodology. Ecoinvent Rep, 1.

32. Bilan produit ADEME, Bilan Produit 2008, http://w ww.ademe.fr/bilanproduit/

33. ISO 14040:1997. Environmental management-lif e cycle assessment - principles and framework.

34. Morbidoni, A., Favi, C., \& Germani, M. (2011). CA D-Integrated LCA Tool: Comparison with dedicate d LCA Software and Guidelines for the improveme nt. Glocalized Solutions for Sustainability in Manuf acturing, 569-574.

35. Guinée J., Heijungs R. (1992): Environmental life c ycle assessment of products: Guide, CML, Leiden, The Netherlands.

36. Gaha, R., Benamara, A., \& Yannou, B. (2015). An Environmental Impact/Cost Model for Evaluating Multiple Feature-Based Machining Methods. In De sign and Modeling of Mechanical Systems-II (pp. 2 1-27). Springer International Publishing.

37. Gaha R., Yannou B., Benamara A. (2014) 'A New Eco-design Approach on CAD systems', Internatio nal Journal of Precision Engineering and Manufact uring, vol. 15 , no. 7 (july 2014), pp. 1443-1451, do i: $10.1007 / \mathrm{s} 12541-014-0489-4$ 